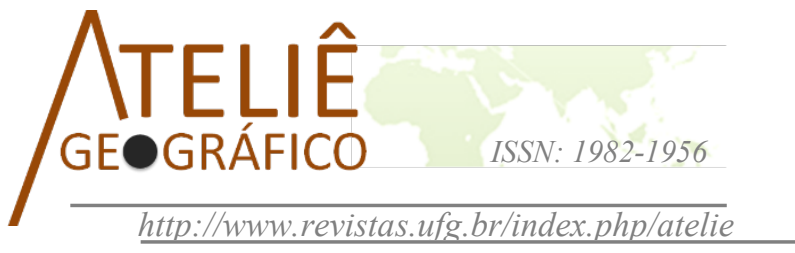

\section{Sistemas, Caos e o Processo de Desertificação no Semiárido Brasileiro: complexidade e interações}

\author{
Systems, Chaos and the Desertification Process in the \\ Brazilian Semiarid: complexity and interactions
}

Sistemas, Caos y el Proceso de Desertificación en el
Semiarido Brasileño: complejidad e interacciones

Jeferson Emanuel de Lemos

Universidade Federal da Paraíba

jefersonlemos88@gmail.com

Bartolomeu Israel de Souza

Universidade Federal da Paraíba

bartolomeuisrael@gmail.com

Marco Túlio Mendonça Diniz

Universidade Federal do Rio Grande do Norte

tuliogeografia@gmail.com

\section{Resumo}

O pensamento sistêmico passou a se destacar a partir da metade do século XX, por volta de 1950, e reverberou seus preceitos em direção a todos os campos do conhecimento, inclusive na Geografia. Realizamos uma revisão teórica de parte da evolução desta noção no seio científico, incluindo questões ligadas à evolução da Teoria do Caos, pois ambos tornam-se complementares e importantes na compreensão do funcionamento dos sistemas complexos. Por se tratar de um trabalho de caráter teórico, foram realizadas discussões embasadas em vários autores, os quais tratam da complexidade tanto na perspectiva científica, quanto da complexidade das interações entre os sistemas sociais e ambientais, bem como da desertificação no semiárido. Tomamos como exemplo de sistema complexo e objeto de análise o semiárido brasileiro, ao elaborar discussões e tentativas de ilustração dessa relação através das dinâmicas socioambientais e espaciais associadas ao processo de desertificação que tem atingido essa área do país. Os principais resultados constatados revelam que este sistema é mantido por meio da interrelação de vários elementos, os quais o tornam complexo e apto a suportar as variações/inputs internos/externos que podem "abalar" sua estrutura de funcionamento. Contudo, devido às constantes reorganizações propiciadas pelos desmatamentos seculares, 
essas intervenções humanas têm gerado um padrão caótico que, se continuar sendo constantemente retroalimentado, pode conduzir todo o sistema semiárido ao estado de desintegração/colapso.

Palavras-chave: Pensamento sistêmico, Caoticidade, Não-linearidade, Complexidade, Caatinga.

\begin{abstract}
The Systemic Thinking rose in notoriety by the first half of the XX century, around 1950, and reverberated its precepts to every field of knowledge, including Geography. We made a theoretical revision about the evolution of this concept on the scientific field, including to the Theory of Chaos, since both became complementary and important for the understanding of the inner workings of complex systems. By being a theoretical work, discussions were realized under the the research of various authors, whose works dealt with the complexity of the topic on a scientific perspective and the complexity of its interactions between social and environmental systems, as well as the desertification of the semiarid. We took as an example of complex system and object of analysis the brazilian semiarid, by elaborating discussions and attempting to illustrate this relationship through the socioambiental and spatial dynamics associated with the desertification process that has struck some areas of Brazil. The main results reveal that this system is maintained by the interrelation of various elements, which make it complex and fit to support variations/internal and external inputs that could "shake" it's structure. However, due to constant reorganizations carried out by centuries of deforestation, those human interventions have created a chaotic pattern which, if kept, may lead the entire semiarid system to a state of disintegration/collapse.
\end{abstract}

Keywords: Systemic thinking, Chaoticity, Nonlinearity, Complexity, Caatinga.

\title{
Resúmen
}

El pensamiento sistémico comenzó a destacarse desde mediados del siglo XX, alrededor de 1950, y reverberó sus preceptos hacia todos los campos del conocimiento, incluida la Geografía. Llevamos a cabo una revisión teórica de parte de la evolución de esta noción dentro del ámbito científico, incluidos los temas relacionados con la evolución de la teoría del Caos, ya que ambos se vuelven complementarios e importantes para comprender el funcionamiento de sistemas complejos. Debido a que es un trabajo teórico, se llevaron a cabo discusiones basadas en varios autores, que abordan la complejidad desde la perspectiva científica, así como la complejidad de las interacciones entre los sistemas sociales y ambientales, así como la desertificación en el semiárido. Tomamos como ejemplo de sistema complejo y objeto de análisis el semiárido brasileño, elaborando debates e intentos de ilustrar esta relación a través de las dinámicas socioambientales y espaciales asociadas con el proceso de desertificación que ha afectado a esta área del país. Los principales hallazgos muestran que este sistema se mantiene a través de la interrelación de varios elementos, lo que lo hace complejo y capaz de soportar las variaciones/entradas internas/externas que pueden cambiar su estructura operativa. Sin embargo, debido a la constante reorganización que brinda la deforestación secular, estas intervenciones humanas han generado un patrón caótico que, si se retroalimenta continuamente, puede llevar a todo el sistema semiárido a un estado de desintegración/colapso.

Palabras clave: Pensamiento sistémico, Caoticidad, No linealidad, Complejidad, Caatinga. 


\section{Introdução}

Os entendimentos quanto a noção de uma natureza dinâmica e processual penetraram fortemente nas ciências no século XX. O principal paradigma ou forma de pensar que sustentou essa maneira de enxergar a realidade veio a partir da noção de sistemas, ou seja, da ideia de que as dinâmicas sociais e naturais funcionariam de forma integrada. Outra noção que ganhou respaldo e participou deste arcabouço foi a de Caos, a qual discorda com a ideia de ordem e linearidade nos sistemas como um todo, mesmo nos mais simples.

A Geografia foi uma das ciências que se deixou influenciar por tais perspectivas, principalmente a partir de 1950 e 1960, junto às discussões em torno da revolução teorético-quantitativa,. Até os dias atuais essa abordagem continua reverberando nas suas práticas de pesquisa, seja nas reflexões teóricas ou nas atividades práticas.

O trabalho que ora apresentamos pretende realizar uma revisão teórica de como se deu parte da evolução da noção de sistemas no seio científico, incluída nesse movimento a Teoria do Caos. O conhecimento destas ajudará o leitor na compreensão do funcionamento dos sistemas complexos. Além disso foi realizada uma discussão e tentativa de ilustração dessa relação através das dinâmicas relacionadas ao processo de desertificação que tem atingido o semiárido brasileiro.

Realizamos esse movimento pois para a devida compreensão dos processos de desertificação que se sucedem no semiárido nordestino (bem como em tantos outros), o geógrafo que deseja pesquisá-lo deve conhecer as características geoambientais e as configurações socioeconômicas. Assim, o viés sistêmico sustenta o modo de estudar a complexidade dos processos. Nesse contexto, concordamos com Christofoletti (1987, p. 126), o qual afirma que:

a preocupação com os impactos ambientais é tarefa inerente à atividade do geógrafo, com toda a sua potencialidade aplicativa, mas para [a sua devida compreensão e] a sua execução há necessidade de se obter conhecimento adequado dos processos, do funcionamento e equilíbrio do geossistema, dos limiares dos fenômenos e da interação com as atividades humanas (CHRISTOFOLETTI, 1987, p. 126).

Para tanto, o trabalho está dividido em 4 seções: A evolução da noção de sistemas; Os sistemas dinâmicos não-lineares; A Teoria do Caos; Os sistemas dinâmicos e o limiar do caos no semiárido brasileiro: o processo de desertificação.

Por ser um artigo de cunho teórico, o trabalho foi elaborado a partir das discussões de alguns autores selecionados, presentes nas reflexões e nas referências ao longo de todo o texto, os quais têm abordado e debatido sobre os temas em destaque a diversos anos, contribuindo assim para a reflexão e problematização no Brasil e no mundo. 


\section{A evolução da noção de sistemas}

A noção de sistema vem em contraposição a uma maneira de pensar anteriormente vigente na ciência ocidental, de base cartesiana e newtoniana, a qual via a realidade como possuidora de lei e ordem. Para os cientistas imbuídos nessa maneira de enxergar a realidade, os fenômenos poderiam ser subdivididos em várias partes para serem analisados sem que estas subdivisões alterassem as suas características.

No entanto, com a "chegada" da física quântica no início do século XX, o pensamento cartesiano não conseguia explicar a realidade como um todo. Isto porque essa se apresentava “...complexa, integrada e por vezes caótica” (VICENTE \& PEREZ FILHO, 2003, p. 329). Assim, teve início a mudança de paradigma no mundo das ciências "hard" abrindo-se a possibilidade de pensar que as proposições ao invés de serem contraditórias eram, ou podiam ser, complementares, como afirmou Bohr. Portanto, “... isso exige uma nova forma de pensar, um pensamento complexo que permita abordar as contradições, em vez de tentar excluí-las" (VASCONCELLOS, 2002, p. 107).

Também no século XX, e principalmente na sua segunda metade, já com influência da física quântica, tiveram início as teorias sistêmicas com o biólogo Ludwig Von Bertalanffy, a qual possui como ideia principal a de que "o todo é mais do que a soma das partes". Diferentemente da ciência clássica, a Teoria Geral dos Sistemas (TGS) não busca solucionar problemas ou tentar soluções práticas, mas produzir teorias e formulações conceituais para aplicações na realidade empírica e que considerem a maior parte de elementos possíveis para compreender o sistema em sua amplitude, numa visão holística. Os sistemas são divididos em abertos e fechados. Nos abertos, ocorrem trocas constantemente entre energia e matéria com o seu meio, enquanto nos fechados isso não acontece (BERTALANFFY, 2010).

Outras duas teorias importantes para compreender o "todo sistêmico" foram as teorias Cibernética e da Informação (MORENO, 2002a; 2002b). A primeira se diferencia da TGS pelo seu objeto de estudo que são as máquinas ou autômatos. Seu idealizador, Norbert Wiener, devido ao contexto e necessidade da época, que era da criação de novas ferramentas e armas para fins militares na Segunda Guerra Mundial, conseguiu desenvolver o princípio da retroalimentação ou feedback, o qual rompeu com o da causalidade linear, dominante até então, e apresentou a ideia de círculo causal, onde: A age sobre B e B atua, em retorno, sobre A. Segundo Morin (2000, p. 202):

O círculo de retroação (denominado feedback) permite, sob a sua forma negativa, estabilizar um sistema, reduzir o desvio, como é o caso da homeostasia. Sob sua forma positiva, o feedback é um mecanismo amplificador, por exemplo, na situação de agravamento dos extremos de um conflito armado. A violência de um protagonista conduz a uma reação violenta, que, por sua vez, leva a uma reação ainda mais violenta. Essas retroações, inflacionistas ou estabilizadoras, são legiões de fenômenos econômicos, sociais, políticos ou psicológicos. 
Quanto à Teoria da Informação, ela está intimamente ligada à Cibernética, assumiu papel de programadora dos autômatos cibernéticos, ao enviar-lhes informações para que mantivessem a ordem (negentropia) frente à desordem (entropia). Desta maneira, é a informação que controla a energia a ser gasta e o que dá independência a uma máquina (MORENO, 2002b).

Com a "reunião" dessas teorias emerge a noção de fenômenos organizados, culminando no início da Teoria da Auto-organização, tendo como foco a relação causal entre a ordem e a desordem. Com a descoberta do princípio da "ordem a partir do ruído" (order from the noise) por Von Foerster (DUTRA-GOMES, 2008), observa-se o surgimento ou formação da ordem a partir da desordem.

Os sistemas aptos a tal estado de criação, ou seja, à auto-organização, seriam apenas os sistemas abertos, os quais mantêm constante troca de matéria e energia com o meio, e a partir desta troca realizariam a auto-organização, surgindo daí a ordem (neguentropia) a partir da desordem (entropia).

Esse mecanismo de auto-ordenamento vai além da noção de retroalimentação e de causalidade circular dos mecanismos retroativos (os feedbacks), que seriam de regulação mais simples (como as máquinas e autômatos, sistemas de refrigeração etc.), para ampliar e referir-se a mecanismos recursivos mais complexos (como sistemas ambientais ou sociais, por exemplo). Segundo Morin (2000, p. 204-205):

O princípio da recursão organizacional vai além do princípio da retroação (feedback); ele ultrapassa a noção de regulação para aquele de autoprodução e autoorganização. É um círculo gerador no qual os produtos e os efeitos são eles próprios produtores e causadores daquilo que os produz. Dessa maneira, nós, indivíduos, somos os produtores de um sistema de reprodução oriundo de muitas eras, mas esse sistema só pode se reproduzir se nós próprios nos tornarmos os produtores nos acoplando.

O quadro no qual se insere a noção de sistemas se mostra como um movimento multidisciplinar que tenta restabelecer a unidade no estudo da natureza e dos seres humanos, que estaria perdido com a divisão compartimentada do conhecimento decorrente do cartesianismo. Além de ter sua origem nas teorias anteriormente citadas (TGS, Cibernética, Informação), ressaltam-se também as contribuições da Física, com importância especial às teorias do Caos e dos Sistemas Dinâmicos.

\section{Os sistemas dinâmicos não-lineares}

Os sistemas dinâmicos não-lineares são o fundamento físico-causal que explica a possibilidade da matéria adquirir novas formas através das adaptações por ela sofridas ao longo do tempo.

A ciências "tradicional", de base cartesiana/newtoniana, que dominou e domina (mesmo que em menor grau) o pensamento científico ocidental durante mais ou menos quatro séculos, acreditava que o tempo não existia, sendo apenas fruto da imaginação humana, e que todas as matérias do universo (árvores, rios, oceanos, seres vivos, 
planetas etc.) não passavam por evoluções, mas todas essas materialidades “já eram”, "já estavam". Buscava-se apenas a essência do objeto, sem olhar as suas circunstâncias. Uma das crenças principais da ciência deste período era, segundo Vasconcellos (2002, p. 66-69):

- A crença na estabilidade do mundo, ou seja, a crença em que o mundo é um mundo estável, que já é como é, e de que podemos conhecer os fenômenos determinados e reversíveis que o constituem, para poder prevê-los e controlá-los.

- (...) Ligados a esse pressuposto estão a crença na determinação - com a consequente previsibilidade dos fenômenos - e a crença na reversibilidade - com a consequente controlabilidade dos fenômenos.

O mundo seria, portanto, estável e isento de uma evolução/movimento, de "tornar-se", de "vir a ser", sendo tomado como um sistema fechado e em eterno equilíbrio. Contudo, no final do século XIX com a termodinâmica, e principalmente no século XX, com o advento da teoria da Relatividade e da teoria Quântica, tem início, na ciência ocidental, a mudança de uma perspectiva cosmológica e microscópica estática para uma mais dinâmica e processual (DUTRA-GOMES, 2008).

Com base no exposto anterior, o século XX constituiu-se num período que marcou a mudança de perspectiva de uma visão de conhecimento representada em termos de trajetórias mecânicas, de bases newtonianas, para uma visão processual e descrita em termos de possibilidades com o uso de ferramentas estatísticas (PRIGOGINE, 1978).

A abordagem sistêmica, entre as décadas de 1950 e 1960, surgiu como opção de busca por uma natureza evolutiva/processual, funcionando como uma relevante ferramenta para o estudo científico dos mecanismos funcionais dos processos. Porém, grande parte de seus entendimentos carregaram, naturalmente, uma forte herança dos paradigmas tradicionais mecanicistas do conhecimento moderno. Ainda assim, o pensamento sistêmico realizou avanços significativos, devido a sua maneira de pensar e enxergar o mundo.

Dessa forma, os avanços realizados a partir da "ordem a partir do ruído" de Von Foerster (DUTRA-GOMES, 2008) e da noção de auto-organização contribuiu para que a Teoria dos Sistemas Dinâmicos Não-Lineares pudesse demonstrar que mesmo pequenas mudanças nas condições iniciais de um sistema poderiam, ao longo do tempo e através de posteriores interações, levá-lo a muitas variações de estado (VASCONCELLOS, 2002; MORIN, 2000; DUTRA-GOMES, 2008).

Outra descoberta importante e inesperada foi que, longe do equilíbrio termodinâmico, a matéria pode adquirir novas propriedades também dinâmicas. Logo, a noção de auto-organização tornou-se de elevada importância para esse quadro teóricoconceitual, visto que, através dela, houve a possibilidade de constituição e realce da importância da desordem nos processos dinâmicos e criativos da natureza, conduzindo o 
sistema a novos arranjos (DUTRA-GOMES, 2008). Dessa forma, surge a Teoria do Caos, discutida a seguir.

\section{A Teoria do Caos}

Advinda da evolução nos estudos dos sistemas dinâmicos não lineares, a noção de Caos foi uma das principais heranças da nova maneira de enxergar a realidade. A principal característica atribuída aos fenômenos caóticos é a da sensível dependência ou susceptibilidade às condições iniciais (SCI) (GLEICK, 1990). Assim, a Teoria do Caos tem como ideia principal que na maioria dos sistemas naturais ou sociais, pequenas variações nas condições iniciais podem gerar enormes variações ao longo do tempo. Essa noção ficou bastante conhecida como "efeito borboleta" ou em termos científicos, "susceptibilidade às condições iniciais" (GLEICK, 1990).

O Efeito Borboleta recebeu um nome técnico: dependência sensível das condições iniciais. E a dependência sensível das condições iniciais não era uma noção totalmente nova. Tinha lugar no folclore: "Por falta de um prego, perdeu-se a ferradura; Por falta de uma ferradura, perdeu-se o cavalo; Por falta do cavalo, perdeu-se o cavaleiro; Por falta do cavaleiro, perdeu-se a batalha; Por falta da batalha, perdeu-se o reino!" (GLEICK, 1990, p. 20).

As discussões sobre o Caos foram iniciadas na ciência no final do século XIX com Henri Poincaré (1854-1912), o qual se viu envolvido no problema da interação newtoniana de três corpos maciços (o Sol, Terra e a Lua). Através de seus estudos Poincaré descobriu que este sistema "tripolar" sempre progredia para formas de equilíbrios irregulares, tornando a sua interação caótica e complexa.

A curto prazo esse sistema possui determinada estabilidade das equações. Contudo, atribuindo-se longos períodos, as séries divergiam grandemente. Ficou evidente que essa pequena divergência provocaria um efeito amplificado que não poderia ser previsto, tornando impossível a possibilidade de prognose do sistema (DUTRA-GOMES, 2008).

Dessa forma, tem fim a ideia de um universo equilibrado, estável, regular e imutável, proconizada pela ciência até então, visto que um sistema composto por apenas três corpos evoluía de maneira a gerar desestabilizações que poderiam, se adequadamente retroalimentadas (feedbacks), levar o sistema a movimentos aleatórios e/ou caóticos. Estabelece-se, com isso, a distinção entre sistemas estáveis e instáveis, com a maior parte dos sistemas da natureza encaixando-se na segunda categoria (DUTRA-GOMES, 2008).

Mesmo com esse início, devido às barreiras teóricas e ao apego aos antigos paradigmas vigentes - causalidade linear, determinismo, mecanicismo newtoniano, racionalidade etc. - (PRIGOGINE, 1996; PRIGOGINE, 2002), essas considerações só foram realmente consideradas no meio acadêmico-científico a partir da segunda metade do século XX, após o desenvolvimento das teorias sistêmicas, aproveitando esse novo momento do fazer e pensar a ciência. 
Como o Caos é um fenômeno no qual elementos dinâmicos conseguem produzir efeitos e variáveis ao longo do tempo que se tornam praticamente imprevisíveis em sua totalidade, visto que os padrões podem variar a partir das mais sensíveis mudanças, a Ciência passa cada vez mais a trabalhar com a idéia matemática de probabilidade. Foi inicialmente no campo da Meteorologia, com Edward Lorenz (19172008), que essa questão se destacou. Através da tentativa de melhoria das modelagens de previsões atmosféricas descobriu-se, por simulação estatística em computadores superpotentes, as propriedades essenciais do caos:

O caos criou técnicas especiais de uso dos computadores e tipos especiais de imagens gráficas, fotos que apreenderam uma fantástica e delicada estrutura subjacente à complexidade. A nova ciência gerou sua linguagem própria, um elegante jargão de fractais e bifurcações, intermitências e periodicidades, difemorfismo folded-towel e mapas smooth noodle. São novos elementos do movimento, tal como na física tradicional, quarks e gluons são os novos elementos da matéria. Para alguns físicos, o caos é antes uma ciência de processo do que de estado, de vir-a-ser do que de ser (GLEICK, 1990, p. 4).

Ao realizar uma simulação com os dados anteriormente coletados num computador que aceitava seis dígitos, Lorenz (1963) deixou de incluir os três últimos, imaginando que a diferença seria irrisória para a evolução do sistema. Mas o que se viu foi que, enquanto no início da trajetória os gráficos convergiam, com o passar do tempo os caminhos divergiam totalmente, e toda a semelhança inicial se perdeu com o tempo e com o decorrer dos acontecimentos. Nesse caso:

Um pequeno erro numérico era como uma pequena brisa passageira - sem dúvida as pequenas brisas desapareciam ou se neutralizavam mutuamente antes que pudessem alterar aspectos importantes, em grande escala, do tempo. Mas, no sistema específico de equações de Lorenz, os pequenos erros mostravam-se catastróficos (GLEICK, 1990, p. 14).

O principal entendimento e/ou reflexão deixados por Lorenz (1963), é o da impossibilidade de previsão completa da evolução dos sistemas dinâmicos, pois pequenas variações podem causar perturbações que podem ser amplificadas, de maneira a tornarem totalmente incertos os eventos futuros do sistema. Por outro lado, isso também não quer dizer que tais sistemas dinâmicos não detenham propriedades determinísticas em relação a sua evolução. Mas, sim, que as regras e padrões do sistema sofreriam perenes perturbações com possibilidades variáveis de lhes proporcionar regimes transitórios e alterações amplificadas de estados no sistema (DUTRA-GOMES, 2008). Portanto, "a ordem surge espontaneamente nesses sistemas - o caos e a ordem, juntos" (GLEICK, 1990, p. 7).

Destacamos que os sistemas dinâmicos, apesar de sensíveis às condições iniciais, não são determinados por elas, renovando suas possibilidades com as decorrentes e posteriores interações. Nesse contexto: 
Sabe-se muito bem, tanto na ciência como na vida, que uma cadeia de acontecimentos pode ter um ponto de crise que aumente pequenas mudanças. Mas o caos significa que tais pontos estavam por toda parte. Eram generalizados. Em sistemas como o tempo, a dependência sensível das condições iniciais era consequência inevitável da maneira pela qual as pequenas escalas se combinavam com as grandes (GLEICK, 1990, p. 20).

Para tanto, os fenômenos e dinâmicas evolutivas dos sistemas naturais apresentam-se em um caráter de complexidade irredutível. Do ponto de vista da aceitação dessas idéias:

Embora apresentando reticências por alguns pesquisadores, este contexto de entendimentos tem sido expressado na comunidade científica para englobar e ultrapassar aquele paradigma moderno a partir da noção de incerteza, ou caos determinístico, demonstrando a necessidade de se incluir os comportamentos complicados e caóticos na descrição determinística da natureza (JONES, 1990, p. 546).

Vale ressaltar que, em princípio, seguimos em consonância com as ideias defendidas na segunda metade do século passado por James Lovelock sobre a hipótese/teoria Gaia - na qual os elementos orgânicos e inorgânicos do nosso planeta evoluíram em conjunto, formando um só sistema integrado, em constante evolução, mantidos por autorregulações, e que conseguiram equilibrar as perturbações introduzidas no sistema, criando toda uma estrutura que proporcionou a origem da vida.

Contudo, concordamos também com a proposta de atualização dessa teoria, publicada recentemente por Tim Lenton e Bruno Latour (LENTON ; LATOUR, 2018) que está mais próxima do nosso trabalho - a qual considera a Terra como um todo complexo e capaz de se auto organizar, mas talvez a diferença fundamental entre elas seja a de que na última, dá-se maior relevância à ação humana como fator importante na criação de novos arranjos ambientais, os quais incidirão nas auto organizações nas mais diversas escalas planetárias.

No contexto anteriormente destacado, esses autores tentam nos alertar para o fato de que, se soubermos manejar o planeta de maneira adequada, criando o que eles chamam de "Self-Awareness" (Autoconsciência, em tradução livre) - ou seja, alimentando e difundido práticas que contribuam para um equilíbrio sadio entre a esfera social e a natural - poderemos dar subsídios para uma "Earth's self-regulation" (Autorregulação da Terra, também em tradução livre).

Isto quer dizer que, de maneira geral, se os homens e mulheres de nosso tempo tomarem consciência e, além disso, produzirem novos padrões de arranjos, mais harmônicos e racionais, conseguirão gerar inputs apropriados à manutenção da vida no nosso planeta. Ou seja, um novo tipo de auto-organização torna-se possível e dominante à medida que geramos impactos positivos no sistema-Terra.

A região do semiárido do Nordeste brasileiro é um laboratório interessante para se trabalhar os aspectos teóricos tratados acima, visto que é uma área que faz parte de 
um sistema natural integrado - o bioma Caatinga -, em constante evolução, mantido por autorregulações, mas que tem sofrido elevada degradação ao longo do tempo, devido às ações humanas, as quais têm sido um fator importante na criação de novos arranjos ambientais, dentre eles a desertificação.

\section{Os sistemas dinâmicos e o limiar do caos no semiárido brasileiro: o processo de desertificação}

A noção de interconectividade espacial da teoria quântica converge com os ensinamentos de que, nas hierarquias escalares dos sistemas, o local, individual e contingente, pode, de acordo com a situação, influenciar as escalas supra-locais ou regionais e, se em condições favoráveis, do geral/global.

No caso das zonas de clima semiárido e, em particular o bioma Caatinga, a atuação secular de retirada da cobertura vegetal tem sido o principal desencadeador da desertificação nessa parte do Brasil, entendida como um processo de degradação que leva determinadas áreas a se transformarem em desertos climáticos ou cujo sistema funciona parcialmente como este bioma (PAN-BRASIL, 2005). Esse fenômeno tem sido estudado no Brasil desde os anos 1970, através dos trabalhos de Vasconcelos - Sobrinho (1976), Ab'Saber (1977), Monteiro (1983), Nimer (1988), Sales (2002), Nascimento (2013), Souza (2008), entre outros.

Destacamos ainda que, com a atuação humana associada aos cenários de projeção climática, é prevista uma contração ainda maior da vegetação atual e o estabelecimento de uma área de clima árido nessa parte do país (NOBRE; OYAMA, 2003), para a qual, localidades com semiaridez acentuada e limites pedológicos (pouca profundidade e/ou problemas de salinização) deverão estar entre as mais afetadas, uma vez que já apresentam limitações geoecológicas naturais ao estabelecimento de uma maior cobertura vegetal, formando geótopos áridos, conforme observações de Ab'Saber (1977).

Parte desse processo de desertificação e do seu efeito em cadeia já é perceptível em algumas áreas da Caatinga, inclusive em escala local e regional, como destacado no trabalho de Souza (2008) e Souza et al. (2015) no Cariri paraibano. Nesse contexto, com a retirada excessiva e contínua da cobertura vegetal, temos a elevação da radiação solar a partir da exposição do solo. Devido à elevação da temperatura superfícial e subsuperficial, sementes de diversas espécies outrora depositadas não têm conseguido germinar, já que existe um limite de temperatura para que esse processo ocorra, dificultando a realização de parte da sucessão ecológica em consequência de tamanha alteração em parte do sistema.

Ainda com base na discussão anterior, mesmo que o padrão de chuvas não seja alterado, a elevação do aquecimento do solo irá induzir ao aumento da evapotranspiração, o que reduz a reserva de água disponível no solo, dificultando a colonização dessas áreas por espécies vegetais mais exigentes em recursos hídricos (NOBRE; OYAMA, 2003; SALAZAR et al., 2007), condição intensificada pela redução 
da estabilidade dos agregados do solo através da retirada excessiva da cobertura vegetal que resulta na formação de crostas e diminuição das taxas de infiltração (LUIJK et al., 2013; MILLS \& FEI, 2004; THUROW, 2000). Ao levar em consideração que a queda na disponibilidade de água aumenta o stress fisiológico das plantas e diminui a produção de biomassa, haverá então, além da menor capacidade de germinação de sementes de diversas espécies, a destruição de muitos indivíduos adultos sensíveis a essa situação ecológica (ENGELBRRECHT et al., 2014; SANTOS et al., 2014).

Acontecerá assim uma modificação não apenas na fisionomia da paisagem, expressa visualmente pela rarefação da cobertura vegetal, em quantidade e diversidade, mas também em parte do sistema, o qual passará a funcionar, pelo menos parcialmente, como um ambiente de clima mais seco em escala local, talvez até mesmo semidesértico, sem que necessariamente o padrão regional da pluviosidade tenha sido alterado. A mudança no estado de equilíbrio do sistema semiárido, ou a sua perda de resiliência, pode ser entendida como uma ruptura (caos/colapso) na capacidade de regeneração das funções ecossistêmicas, com perdas praticamente irreversíveis e custos de recuperação altíssimos.

Cabe destacar que recentemente Medeiros et al. (2017) defendem a ideia de que, em sistemas dinâmicos complexos, dentre os quais faz parte a Caatinga, ocorrem perturbações intensas, o limite crítico que dá suporte a sua resiliência pode ser ultrapassado, e chegar a uma situação praticamente irreversível, como exemplo a desertificação. Isso também significa que, mesmo ainda existindo indivíduos de certas espécies vegetais consideradas essenciais para o funcionamento do sistema, o que poderia dar a impressão de que o ambiente pode se recuperar espontaneamente, elas teriam ultrapassado um ponto sem retorno, estando submetidas à extinção.

Reforçando a ideia acima, Morante-Filho et al. (2017) destacam que, no caso das aves, a substituição das espécies que vivem em florestas e evoluíram nesse ecossistema, por outras generalistas, capazes de se adaptar a ambientes degradados, embora inicialmente façam acreditar que o ambiente está se recuperando, na verdade esconde o fato de que interações ecológicas fundamentais foram perdidas e não podem ser compensadas pelo aumento da diversidade filogenética de aves generalistas de habitats a curto prazo.

$\mathrm{O}$ enunciado anterior também pode ser aplicado à Caatinga, um bioma originalmente florestal, parte das Florestas Sazonalmente Secas do mundo (SDTFs, em inglês, cf. RITO et al., 2016), no qual o papel de dispersão de sementes é majoritariamente efetuado por animais (GOMES; QUIRINO, 2016).

Fica claro, dessa maneira que, se o sistema é continuamente submetido à alteração em suas condições originais (estabelecidas após centenas de anos), passa por um período inicial de aumento de pressão até atingir o ponto em que não é mais possível realizar a neguentropia/ordem, ou, em termos ambientais, perde a resiliência, como na desertificação. O retorno à estabilidade no sistema, como na condição inicial de outrora é praticamente impossível. 
Entretanto, apesar de agora não estar em condições semelhantes aos originais, esta fase do sistema expressa uma grande capacidade organizacional. Assim, a organização deste e de outros sistemas ambientais não é passiva, mas sim ativa, gerando a dinâmica que a produz (retroalimentação), e vai além da retroação. Nesse caso, a dinâmica sistêmica deve ser recursiva e dialógica, o que implicará a concepção de uma dinâmica não-linear recursiva (complexa), interativa e auto-organizadora dos sistemas naturais (CARACRISTI, 2007). Portanto, o processo de desertificação:

(...) é um sistema auto-organizador, criado e regulado pelas mesmas mudanças não-lineares que criam a agitação imprevisível à sua volta. É o caos estável (...) ilhas de estrutura podem aparecer dentro da desordem (...) um sistema complexo pode dar origem à turbulência e à coerência ao mesmo tempo (GLEICK, 1990, p. 51).

Reafirmamos que, apesar de toda a interferência provocada pelas ações da sociedade, o novo padrão que se configura é fruto das retroalimentações do próprio sistema. É o que explica Caracristi (2007, p. 36), a respeito da ocorrência deste processo no semiárido:

Os processos resultam da interação dinâmica das forças e mecanismos que são gerados segundo as possibilidades estruturais do sistema. A estrutura gera as possibilidades processuais e é por elas gerada, em um ininterrupto dinamismo de retroatividade, implicando uma dinâmica recursiva (não-linear) e auto-organizativa. As possibilidades estruturais, organizacionais do domínio de relações semi-áridas do nosso território permitem uma tendência à aridez quando submetidas a atividades humanas degradadoras, mas jamais essa tendência se configuraria num padrão típico do deserto saariano, por exemplo. Cada sistema natural carrega seu próprio potencial de derivação, de auto-organização.

Cabe ainda destacar que, em toda essa discussão, percebemos que o limite entre os conceitos de deserto e desertificação são muito próximos, o que pode gerar certa confusão, inclusive no meio acadêmico. Nesse caso, cabem algumas considerações.

O deserto é um ecossistema climácico. Para Odum (2012, p. 330) "Teoricamente, a comunidade clímax é autoperpetuante porque está em equilíbrio dentro de si mesma e com o habitat físico, em contraste com uma comunidade desenvolvimental ou outra comunidade transitória". Suas principais características gerais são: 1) normal climatológica da precipitação abaixo de $250 \mathrm{~mm} / \mathrm{ano}$, com grande amplitude térmica diária (tanto no clima árido quente-seco ou frio-seco), 2) desprovido de formações arbóreas $(>8 \mathrm{~m}), 3$ ) presença predominante de poucas e esparsas espécies arbustivas com folhas pequenas e hiperxerofilia; 4) maioria da vegetação é composta por herbáceas sazonais, com ocorrência de espécies suculentas e cactáceas; 5) baixa produtividade (produção de serrapilheira e fixação de $\mathrm{C}$ no solo), 6) baixa diversidade de vida animal (BROWN; LOMOLINO, 2006; CHRISTOPHERSON, 2012; COX; MOORE, 2014; ODUM, 2012).

Ao partir do pressuposto de que deserto é uma região de clima árido (menos de $250 \mathrm{~mm} / \mathrm{ano}$ ), o processo de desertificação, definido como a degradação das terras 
ocasionada por ações antropogênicas e variações climáticas em áreas localizadas nas zonas semiáridas e subúmidas secas (PAN-BRASIL, 2005) não seria, em princípio, a transformação desses espaços como as do semiárido brasileiro em desertos, se considerarmos correta a impossibilidade de se promover em poucas centenas de anos uma mudança climática, particularmente de pluviosidade, dessa magnitude e nessa escala pelas ações humanas, a qual abrange a transformação de um sistema atmosférico global, no caso da parte do Brasil considerada como susceptível a esse processo, particularmente a Zona de Convergência Intertropical (ZCIT).

Contudo, se por um lado a ação humana seria incapaz de transformar um clima semiárido ou subúmido seco em um clima árido propriamente dito, por outro lado a ação antrópica secular nesses ambientes secos do Brasil tem sido capaz de transformar paisagens anteriormente típicas de savanas estépicas ou florestas sazonalmente secas (a primeira, conforme a classificação do IBGE para a Caatinga; a segunda, conforme é mencionada a Caatinga na literatura internacional) em outras não apenas com aparência de deserto, mas também com parte dos processos e da dinâmica característica desses espaços, conforme já discutimos anteriormente.

Ao considerar ainda que transformação é transformar + ação, aqui cabe recorrer ao dicionário Houaiss (2001) para definir a palavra "transformar" que é "fazer tomar ou tomar nova feição ou caráter" ou "fazer passar ou passar de um estado ou condição a outro; converter (-se), transfigurar(-se)".

Para ratificar o que já foi dito em outras palavras, essa degradação das terras nas zonas semiáridas e subúmidas secas é capaz de mudar a feição ou transfigurar as paisagens no Brasil e em outras áreas do mundo de modo que estas se tornem parcialmente semelhantes a desertos, em forma, processos e dinâmicas, ainda que a pluviosidade não venha a ser afetada.

Com base na colocação anterior, no quadro ilustrativo abaixo (Figuras 01a, 01b e 01c), podem ser identificadas empiricamente diversas características de paisagens de clima secos, com aspectos visuais semelhantes, onde se destacam: ausência de vegetação arbórea; presença predominante de poucas e esparsas espécies arbustivas e solo exposto.

A diferença é que as duas primeiras imagens representam um espaço criado predominantemente pela Natureza, um deserto, para o qual vem dominando a atuação de dinâmicas processuais em grande parte isentas da ação humana, estabelecidas ao longo de um tempo geológico (tempo lento), enquanto a terceira imagem as transformações foram criadas pelas intervenções da sociedade, uma área desertificada, na qual tem dominado transformações estabelecidas artificialmente ao longo de um tempo mais recente e de forma acelerada. 


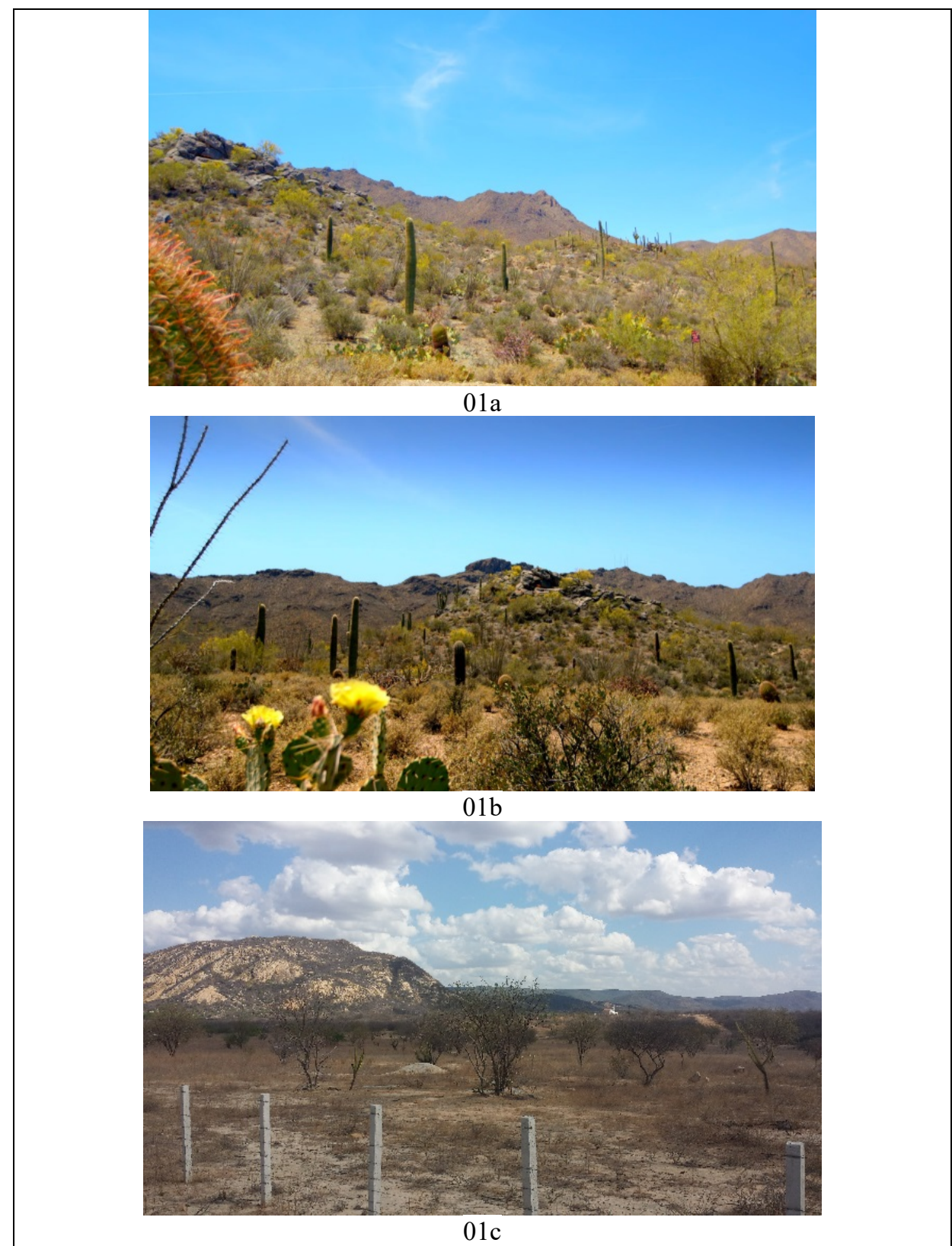

Figuras 01a e 01b: Deserto de Sonora nos EUA. Fonte: https://www.netflix.com/br/title/80213025, 2018.

Figura 1c: Savana Estépica degradada no Brasil, município de Acari - RN. Fonte: fotografia dos autores, 2014. 
Finalmente, ainda que áreas desertificadas como a apresentada na figura $4 c$, não se transformem efetivamente em um deserto, é certo que ao menos parcialmente o sistema Caatinga já foi transfigurado para um estágio com menor biodiversidade e potencial de desenvolvimento econômico, acarretando prejuízos ambientais e socioeconômicos de difícil solução. Isso é facilmente perceptível onde a semiaridez é mais acentuada (menos de $500 \mathrm{~mm} / \mathrm{ano}$, em média), como é o caso das regiões do Seridó (RN e PB) e Cariris Velhos (PB), entre outras que compõem os Núcleos de Desertificação do país (PAN-BRASIL, 2005), onde uma assembleia empobrecida de cobertura vegetal por ações humanas torna esses ambientes mais sensíveis a distúrbios crônicos (RIBEIRO et al., 2015; RITO et al., 2016), quer seja pela continuidade da degradação antrópica, quer seja pela ocorrência de estiagens mais prolongadas, fazendo com que, dialeticamente, causa e consequência do processo se misturem.

\section{Considerações finais}

O sistema semiárido do Nordeste brasileiro é extremamente complexo e mantido através da interrelação de vários elementos. Sua estabilidade está cada vez mais ameaçada em função de diversas atividades humanas, dentre as quais destacamos o desmatamento histórico submetido ao longo do tempo, que tem difundido cada vez mais um padrão caótico que, ao ser constantemente retroalimentado, pode levar parte do sistema ao estado de desintegração ou colapso.

Estudos futuros, pautados no arcabouço teórico-metodológico das contribuições dos paradigmas Sistêmico, da Complexidade e da Teoria do Caos, podem obter um melhor entendimento/descrição do funcionamento e da atividade organizativa do sistema semiárido e do processo de desertificação nele existente, a fim de serem adotadas as ferramentas adequadas para o emprego de técnicas de estudo dos processos evolutivos das áreas em processo de alteração ambiental. Tais pesquisas devem estar vinculadas à técnicas e ferramentas práticas de análise eficazes, para que sejam propostos modelos para o auxílio na recuperação das áreas degradadas e na manutenção ou melhoria das menos afetadas, através da educação ambiental e de intervenções junto aos agricultores, por exemplo.

No contexto das ciências socioambientais, o conhecimento do funcionamento de sistemas complexos como este é fundamental, pois cria-se a consciência de que a alteração de um determinado bioma ou parte deste, pode compreender danos de elevada magnitude, os quais demandarão custos elevados nas áreas já afetadas, e que poderiam e ainda podem ser identificados, mitigados e/ou revertidos, ao menos parcialmente. Nesse caso, essas ações teriam o objetivo justamente de amenizar ou estacionar o "efeito borboleta" e criar uma situação de sustentabilidade econômica, social e ambiental nos ambientes atingidos. 


\section{Referências bibliográficas}

AB'SABER, A. N. A problemática da desertificação e da savanização no Brasil. Campinas: Noticia Geomorfológica, n. 1, p. 24-30, 1958.

BERTALANFFY, L. V. Teoria geral dos sistemas: fundamentos, desenvolvimento e aplicações; tradução de Francisco M. Guimarães. - 5. ed. - Petrópolis, RJ: Vozes, 2010.

BRANCO, E. A. Capital Natural, Crescimento econômico e riqueza: reflexões a partir da abordagem e modelagem de sistemas complexos. 2012. Dissertação (Mestrado) - Escola de Artes, Ciências e Humanidades.São Paulo: Universidade de São Paulo, 2012.

BROWN, J. H.; LOMOLINO, M. V. Biogeografia. 2. ed. Tradução de Iulio F. Afonso. Ribeirão Preto-SP: Editora Funpec, 2006.

CAPEL, H.; URTEAGA, L. Las nuevas geografias. Barcelona: Aula Abierta/ Salvat editores S. A., 1984, 64p.

CARACRISTI, I. Processo de desertificação no nordeste brasileiro. Revista da Casa da Geografia de Sobral, v. 8/9, n. 1, p. 31-43, 2006/2007.

CHORLEY, R.; KENNEDY, B. Physical geography: a systems approach. Londres: Prentice-Hall, 1971,370p.

CHORLEY, R.; HAGGETT, P. (org.) Modelos Físicos e de informação em geografia. São Paulo: Ed. USP, 1975, 260p.

CHRISTOFOLETTI, A. Analise quantitativa em geografia. Geografia, 1 (1): abril 1976, p.109-111.

CHRISTOFOLETTI, A. As características da Nova Geografia. Boletim de Geografia Teorética. 1

(1): abril 1976, p.3-33.

CHRISTOFOLETTI, A. Aspectos da análise sistêmica em Geografia. Geografia, 3 (6): outubro, 1979a, p.1-31.

CHRISTOFOLETTI, A. Análise de sistemas em Geografia. São Paulo: Ed. Hucitec, 1979b, 109p.

CHRISTOFOLETTI, A. As perspectivas dos estudos geográficos. In: CHRISTOFOLETTI, A. (org.) Perspectivas da Geografia. São Paulo: Difel S.A., 1982, 318p.

CHRISTOFOLETTI, A. Significância da Teoria de Sistemas em Geografia Física. Boletim de Geografia Teorética, 16-17 (31-34): 119-128, 1986-1987.

CHRISTOPHERSON, R. W. Geossistemas: uma introdução à geografia física. 7 ed. Porto Alegre: Bookman, 2012.

COX, C. B.; MOORE, P. D. Biogeografia: uma abordagem ecológica e evolucionária. Tradução de Luiz Felipe C. F. da Silva. Rio de Janeiro: LCT, 2009. 
DUTRA-GOMES, R. Geografia e Evolução Paradigmática: Esclarecimentos para o Diálogo Entre os Conhecimentos. Qualificação da Tese de Doutorado. Campinas: UNICAMP/Instituto de Geociências (IG), 2008.

DUTRA-GOMES, R.; VITTE, A.C. A geografia física e o objeto complexo: algumas flexibilizações do processual. Geosul, v. 26, n. 50, p. 8-38, 2010.

ENGELBRECHT, B. M.; COMITA, L. S.; CONDIT, R.; KURSAR, T. A.; TYREE, M. T.; TURNER, B. I.; HUBBELL, S. P. Drought sensitivity shapes species distribution patterns in tropical forests. Nature, 447, p $80-82$.

GLEICK, J. Caos: a criação de uma nova ciência. Tradução de Waltensir Dutra. - Rio de Janeiro: Campus, 1990.

GOMES, P. C. C. Geografia e Modernidade. Rio de Janeiro: Bertrand Brasil, 2000, 366p.

GOMES, V. G. N.; QUIRINO, Z. G. M. Síndromes de dispersão de espécies vegetais no Cariri paraibano. Revista Bras. de Geografia Física, v. 09, n. 04, p. 1157-1167, 2016.

HOUAISS, A. Novo Dionário Houaiss da Línga Portuguesa. Rio de Janeiro: Instituto Antônio Houaiss, 2001.

JONES, R. Determinism in Deterministic Chaos. Proceedings of the Biennial Meeting of the Philosophy of Science Association, Philosophy Science Association, Volume two: Symposia and Invited Papers, 1990, pp.537-549.

LENTON, T. M.; LATOUR, B. Gaia 2.0. Science, v. 361, n. 6407, p. 1066-1068, 2018.

LIMBERGER, L. Abordagem sistêmica e complexidade na geografia. Geografia - v. 15, n. 2 , jul./dez., 2006, p. 95-109.

LORENZ, E. N. Deterministic nonperiodic flow. Journal of the atmospheric sciences, v. 20, n. 2, p. 130-141, 1963.

MEDEIROS, E. S.; CALDAS, I. L.; BAPTISTA, M. S.; FEUDEL, U. Trapping phenomenon attenautes the consequences of Tipping Points for limite cycles. Scientific Reports 7, 42351, 2017.

MENDOZA, J. G., JIMENEZ, J. M., CANTERO, N. O. El pensamiento geográfico. Estudio interpretativo y antología de textos (De Humboldt a las tendencias radicales). Madri: Editoral Alianza, 1988, 545p.

MILLS, A. J.; FEI, M. V. Transformation of ticket to savana reduces soil quality in the Eastern Cape, South Africa. Plant and Soil, 265, p. 153 - 163, 2004.

MONTEIRO, C. A. F. On the desertification in northeast Brazil and man's rote in this process. Latin American Studies, Japão, p. 01-10, 1983.MONTEIRO, C. A. F. Geossistemas: a história de uma procura. 2. ed. - São Paulo: Contexto, 2001.

MORENO, J. C. Fuentes, autores y corrientes que trabajan la complejidad. In: VELILLA. M. A. et al. Manual de iniciación pedagógica al pensamiento complejo. ICFES-UNESCO, Colombia, 2002a. p. 11-24. 
MORENO, J. C. Tres teorías que dieron origen al pensamiento complejo: sistémica, cibernética e información. In: VELILLA. M. A. et al. Manual de iniciación pedagógica al pensamiento complejo. ICFES-UNESCO, Colombia, 2002b. p. 25-37.

MORIN, E.; LE MOIGNE, J. L. A Inteligência da Complexidade. São Paulo: Petrópolis, 2000.

NASCIMENTO, F. R. O fenômeno da desertificação. Goiânia: Ed. UFG, 2013.

NIMER, E. Desertificação: mito ou realidade? Rio de Janeiro: IBGE, Revista Brasileira de Geografia, v. 50, n. 1, p. 7-39, 1988.

NOBRE, C. A.; OYAMA, M. D. A new climate-vegetation equilibrium state for Tropical South America. Geophysical Research Letters, v. 30, n. 23, p. 2199-2203, 2003.

ODUM, E. P. Ecologia. Tradução Christopher J. Tribe. Reimpr. Rio de Janeiro: Guanabara Koogan, 2012.

PAN-BRASIL. Programa de Ação Nacional de Combate à Desertificação e Mitigação dos Efeitos da Seca. Brasília: MMA, 2005.

PRIGOGINE, I. O fim das certezas: Tempo, caos e as leis da natureza. São Paulo: Editora da UNESP, 1996.

PRIGOGINE, I. As Leis do Caos. São Paulo: Editora da UNESP, 2002.

RIBEIRO, E. M. S.; ARROYO-RODRIGUEZ, V.; SANTOS, B. A.; TABARELLI, M.; LEAL, I. $\mathrm{R}$. Chronic antropogenic disturbance drives the biological impoverishment of the Brazilian Caatinga vegetation. Journal of Applied Ecology, 52, p. 611 - 620, 2015.

RITO, K. F.; ARROYO-RODRIGUEZ, V.; QUEIROZ, R. T.; LEAL, I. R.; TABARELLI, M. Precipitation mediates the effect on human disturbance on the Brazilian Caatinga vegetation. Journal of Ecology, November 2016.

SALES, M. C. L. Evolução dos estudos de desertificação no Nordeste brasileiro. São Paulo: GEOUSP - Espaço e Tempo, n. 11, p. 115 - 126, 2002.

SANTOS, M. G.; OLIVEIRA, M. T.; FIGUEIREDO, K. V.; FALCÃO, H. M.; ARRUDA, E. C.; ALMEIDA-CORTEZ, J.; ANTONINO, A. C. Caatinga, the Brazilian dry tropical forest: can it tolerate climatic changes? Theoretical and Experimental Plant Physiology, 26, p 83 - 99.

SALAZAR, L. F.; NOBRE, C. A.; OYAMA, M. D. Climate change consequences on the biome distribution in Tropical South America. Geophysical Research Letters, 34: 1 - 6, 2007.

SOTCHAVA, V. B. O estudo de geossistemas. Métodos em Questão. São Paulo: IG-USP, n.16, $1977,52 \mathrm{p}$.

SOUZA, B. I. Cariri paraibano: do silêncio do lugar à desertificação. Tese. Porto Alegre: UFRGS, Programa de Pós-Graduação em Geografia, 2008.

SOUZA, B. I.; MACÊDO, M. L. A.; SILVA, G. J. F. Temperaturas dos solos e suas influências na regeneração natural da caatinga nos Cariris Velhos-PB. Ra'e ga, v. 35. p. 261 -287, 2015. 
TRICART, J. Ecodinâmica. Rio de Janeiro, IBGE, Diretoria Técnica, Superintendência de Recursos Naturais e Meio Ambiente (SUPREN), 1977.

THUROW, I. L. Hydrologycal effects of rangeland degradation and restoration processes. In: ARNALDS, O. \& ARCHER, S. (Eds.). Rangeland Desertification. Kluwer: Dordrecht, p. 53 - 66, 2000.

VASCONCELLOS, M. J. E. Pensamento Sistêmico - o novo paradigma da ciência. Campinas: Papirus, 2002, 268p.

VASCONCELOS-SOBRINHO, J. O processo de desertificação no Nordeste brasileiro. Brasília: Senado Federal, 1976.

VELILLA, M. A. et al. Manual de iniciación pedagógica al pensamiento complejo. ICFESUNESCO, Colombia, 2002.

VICENTE, L. E.; PEREZ FILHO, A. Abordagem Sistêmica e Geografia. Geografia. Rio Claro: v. 28, n. 3, p. 345-362, set./dez., 2003.

Jeferson Emanuel de Lemos

Mestrando pelo Programa de Pós-Graduação em Geografia (PPGG) da Universidade Federal da Paraíba (UFPB). Centro de Ciências Exatas e da Natureza (CCEN), CEP: 58051-900, Cidade Universitária - João Pessoa-PB - Brasil.

E-mail: jefersonlemos88@gmail.com

Bartolomeu Israel de Souza

Professor do Programa de Pós-Graduação em Geografia (PPGG) da Universidade Federal da Paraíba (UFPB). Centro de Ciências Exatas e da Natureza (CCEN), CEP: 58051-900, Cidade Universitária - João Pessoa-PB - Brasil.

E-mail: bartolomeuisrael@gmail.com

\section{Marco Túlio Mendonça Diniz}

Professor Adjunto da Universidade Federal do Rio Grande do Norte. Centro Regional de Ensino Superior do Seridó, CEP: 59300-000 - Caicó-RN - Brasil.

E-mail: tuliogeografia@gmail.com

Recebido para publicação em fevereiro de 2019 Aprovado para publicação em outubro de 2019 